
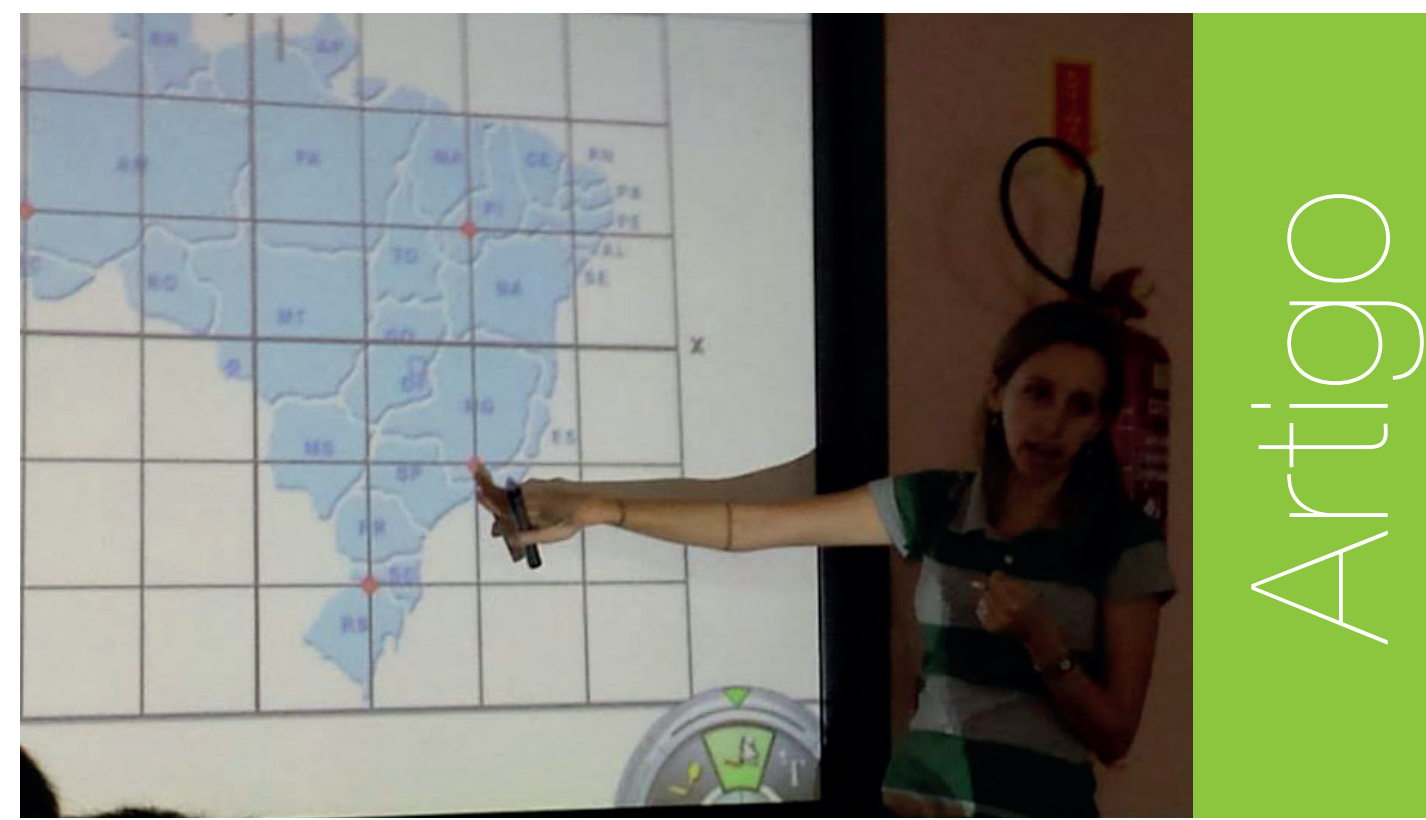

\title{
Relatos de Experiências de Docentes de EJA e Língua Portuguesa: problematizando o uso de tecnologias digitais
}

\author{
Alaim Souza Neto - alaim.souza@ufsc.br ${ }^{1}$
}

\section{RESUMO}

Em meio à demanda por cursos de formação docente sobre 0 uso de tecnologias digitais na sala de aula para ensino dos conteúdos escolares, este artigo discute e problematiza a oferta de um curso de extensão com esse objeto aos professores e futuros professores da educação básica do município de São José/SC. 0 artigo tem como referencial teórico vários autores que problematizam 0 uso de tecnologias digitais (TD) no contexto escolar. Como metodologia, baseando-se na pesquisa-formação, propomos uma discussão teórica seguida de aplicação prática de usos das tecnologias digitais por meio da colaboração, da cooperação e da socialização de experiências docentes que se configuraram ao final do curso em aulas a serem ministradas à comunidade de São José. Como um dos resultados, apontamos a maior segurança dos professores quanto à fluência digital, permitida pela socialização de diferentes experiências de uso das tecnologias digitais na sala de aula.

\section{PALAVRAS-CHAVE}

Tecnologias digitais. Formação docente. Práticas pedagógicas. Docência. Atividades de

1 Doutor e Mestre em Educação com pós-doutorado na mesma área. Professor adjunto na UFSC (Universidade Federal de Santa Catarina) no Departamento de Ciências Exatas e Educação do Câmpus Blumenau. 
extensão.

\section{ABSTRACT}

Faced with a demand for teacher training courses on the use of digital technologies in the classroom to teach school content, this article discusses and problematizes the offer of an extension course with this aim to teachers and future teachers of basic education of the municipality of São José/SC. The theoretical reference of the course is subsidized in several authors that problematize the use of digital technologies in the school context. As a methodology, based on research-training, we propose a theoretical discussion followed by practical application through collaboration, cooperation and socialization of experiences using the digital technologies that were configured at the end of the course in classes to be taught to the community of São José. As one of the results, we point out the greater safety of teachers regarding digital fluency, allowed by socialization of different experiences of using digital technologies in classroom.their attention to health care, their rights as citizens, women, mothers and workers.

\section{KEYWORDS}

Digital technologies. Teacher training. Pedagogical practices. Teaching. Extension activities.

\section{Introdução}

Na contemporaneidade, as discussões sobre as necessidades de mudanças e inovações curriculares ${ }^{2}$ estão continuamente atreladas à implantação de tecnologias digitais na escola (CUBAN, 2001; SOUZA-NETO, 2015). Por diferentes caminhos, os países tecnologicamente avançados, ou em vias de desenvolvimento, têm lançado projetos ambiciosos de alterações das atuais práticas pedagógicas. Nesse sentido, temos nos envolvido com pesquisa, ensino e extensão, relacionando os campos da Educação, Comunicação e Tecnologias Digitais, inserindonos em vários grupos de investigação e projetos de pesquisa33, tais como: 0 projeto "Aulas Conectadas - Mudanças Curriculares e aprendizagem colaborativa entre as escolas do Projeto Um Computador Por Aluno" no estado de Santa Catarina; o projeto de pesquisa "Tablets, Computadores e Laptops: análise sobre políticas, infraestrutura e aspectos pedagógicos da inserção de novas tecnologias na escola"; além de projetos internacionais para a OEI Organização dos Estados Iberoamericanos, sobre o uso e desuso das tecnologias digitais na escola.

Para referenciar as pesquisas, temos nos subsidiado em estudos de Pinto (2005), Feenberg (2003), Cuban (2001), Rabardel (1997, 1995), Almeida (2014), Almeida e Valente (2011), Costa (2012, 2008), Sandholtz; Ringstaff; Dwyer (1997); Sancho; Hernandez (2006); Castells (2003, 1999). Tais autores têm estreita relação com os estudos de Cuban (2001), que aborda em suas últimas pesquisas a forma como os professores trabalham com o computador em suas salas de aula em escolas da região do Vale do Silício. Na outra ponta dessa discussão, tem-se a análise do impacto das políticas educativas sobre a inserção das tecnologias digitais no contexto escolar feita por Sossai, Lunardi-Mendes e Pacheco (2009), Young (2007, 2010), além de outros como Ball (2014).

Desse modo, nossa defesa consiste em afirmar que a inserção das tecnologias digitais na escola, assim como qualquer inserção que se queira operar no cotidiano escolar, precisa

\footnotetext{
2 Por inovações curriculares, compreendemos a proposição de metodologias alternativas para melhor aproveitamento das tecnologias na sala de aula, bem como a construção de comunidades online de aprendizagem colaborativa entre as escolas investigadas e, ainda, a produção de seminários temáticos em torno do debate sobre a inserção de tecnologias digitais no contexto escolar. (LUNARDI-MENDES, 2012).

3 São pesquisas desenvolvidas no âmbito do Grupo de Pesquisa da Udesc, denominado de OPE,2012 Observatório de Práticas Escolares, coordenado pela Profa. Dra. Geovana Mendonça Lunardi Mendes.
} 
necessariamente estar associada à reflexão crítica, teórica e prática sobre os principais fundamentos do currículo e a alterações nos contornos e desenhos de formação docente. Para tanto, valemo-nos de estudos de Libâneo (2012, 2011a, 2011b), Pimenta (2009), Tardif (2013), Shullman $(1986,1987)$ e Bonilla (2012). É a partir desses referenciais que julgamos importante propor experiências de uso das tecnologias digitais entre as práticas dos professores e futuros professores de Educação de Jovens e Adultos (EJA) e Língua Portuguesa como forma de conscientização para a formação docente necessária em tempos em que a cultura emergente se caracteriza pela alcunha de digital. As práticas docentes no ensino de EJA e Língua Portuguesa estão aqui salientadas, porque foram disciplinas curriculares ministradas por nós na graduação do curso de Pedagogia de uma instituiçãã $0^{4}$ pública de ensino superior.

0 objetivo geral do projeto é propor um curso de extensão na modalidade "complementação de estudos", analisando e socializando diferentes formas de apropriação tecnológica de professores, atentando para elementos didático-pedagógicos que revelassem possíveis inovações curriculares ${ }^{5}$ a partir do uso de tecnologias digitais ${ }^{6}$ (computador desktop, laptop, tablet, câmeras e filmadoras, celulares e lousas digitais) nas práticas pedagógicas de EJA e Língua Portuguesa.

Em relação aos objetivos específicos, a intenção do curso de extensão era: problematizar as diferentes formas e meios de apropriação tecnológica dos futuros professores (formação inicial e continuada); compartilhar experiências docentes de uso das tecnologias digitais na sala de aula; diferenciar inovações tecnológicas, inovações curriculares e inovações pedagógicas; elaborar planos de aula que contemplem o uso de tecnologias digitais; socializar os conhecimentos sobre a docência em EJA e docência da Língua Portuguesa a partir de experiências com o uso de tecnologias digitais; contribuir com o fortalecimento e a ampliação do curso de Pedagogia da instituiçã̃o e de suas redes de pesquisa e extensão com propostas de práticas para as escolas da região da Grande Florianópolis; e fortalecer o diálogo entre os acadêmicos do curso de Pedagogia da instituiçãao, professores do curso e os diversos atores envolvidos com a discussão sobre 0 uso das tecnologias digitais no contexto escolar.

A formação de professores foi um dos resultados de alto impacto esperados após a oferta do curso de extensão à comunidade interna do Centro Universitário Municipal de São José, conforme alunos do curso de Pedagogia, bem como a oferta do curso à comunidade externa caracterizada pela presença dos professores da rede pública de ensino do município de São José/SC e demais membros da comunidade interessados na inserção de tecnologias digitais no contexto escolar. Nesse sentido, almejava-se contribuir com a consolidação do curso de Licenciatura em Pedagogia da instituição de ensino superior, por meio do tripé ensino-pesquisa-extensão, favorecendo a construção de redes investigativas não só locais, mas nacionais e internacionais sobre 0 uso de tecnologias digitais na sala de aula em que os alunos do centro universitário, bem como a comunidade externa (professores da rede pública municipal de São José), assumem papel ativo de protagonismo. Além disso, pretendia-se contribuir significativamente com a produção de conhecimentos da área, consolidando e socializando os resultados encontrados em projetos de pesquisa e extensão, envolvendo a inserção de tecnologias digitais nas práticas curriculares.

\section{Metodologia}

Inicialmente, o curso de extensão em forma de complementação de estudos proposto foi elaborado a partir de demandas dos acadêmicos de turmas anteriores em que ministramos as aulas de docência em EJA I e II e Docência em Língua Portuguesa I e II, no curso de Pedagogia

\footnotetext{
4 Trata-se de uma Universidade Pública Municipal do município de São José/SC que oferece os cursos superiores de Pedagogia, Sistemas de Informação, Ciências da Religião, Administração e Ciências Contábeis.

5 Estamos denominando de inovações curriculares, as alterações que são feitas nos processos pedagógicos tradicionais a partir da inserção das tecnologias digitais no currículo (SANCHO, 2009).

6 Quanto ao termo tecnologias digitais, estamos nos referindo às tecnologias a partir da cultura digital, estas relativas ao processo de digitalização com 0 sistema de linguagem binário em contraposição às tecnologias analógicas. Ex. computador, smartphone, câmera digital, projetor multimídia, conforme o concebido por Souza-Neto (2015; 2016).
} 
da instituição de ensino superior, bem como uma demanda educacional por professores mais bem preparados para o uso, inserção e apropriação de tecnologias digitais na sala de aula, dada a ausência de discussões na formação inicial e continuada. Desse modo, o curso tinha alta relevância na atualidade pelo seu ineditismo como proposta de atividade de extensão. Éramos cientes de que realizar uma atividade de extensão com essa envergadura só era possível pelo envolvimento de diferentes pessoas: professores, coordenação de curso, servidores técnicoadministrativos, acadêmicos do curso de Pedagogia e, fundamentalmente, a comunidade externa, constituída por professores da educação básica da rede pública e municipal de ensino, conforme Figura 1, a qual participou na modalidade "curso". 0 resultado desse envolvimento foi a oferta de uma proposta de formação aos professores e futuros professores que desejassem usar as tecnologias digitais em suas práticas pedagógicas com mais segurança e fluência digital.

Figura 1: Professores em formação. Fonte: Fotos do autor (2018).

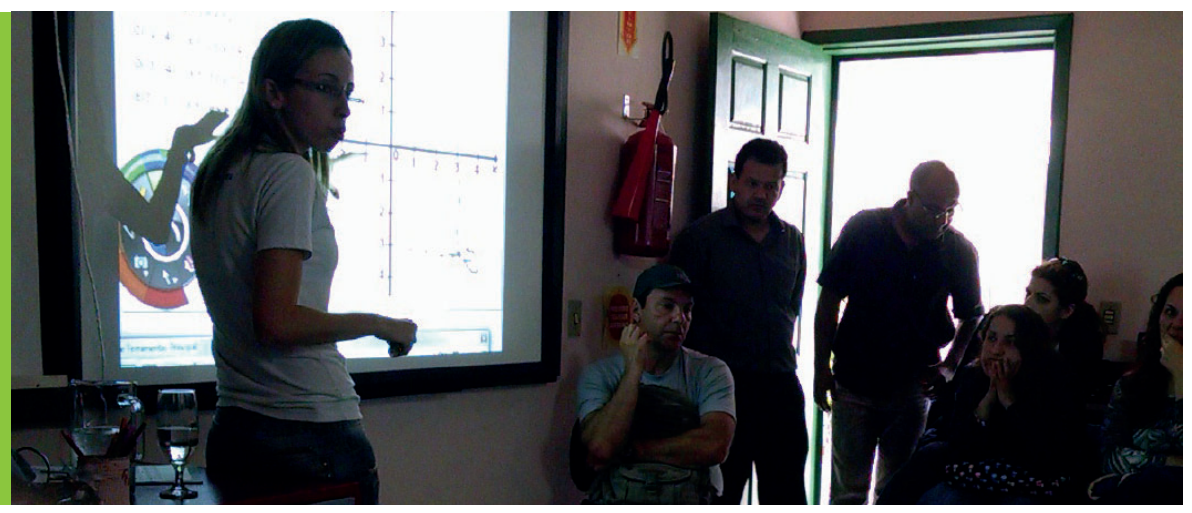

Inicialmente, o desafio foi entusiasmar o grupo de acadêmicos e professores, considerando que se almejava construir uma rede de formadores e formandos, envolvendo diferentes pessoas. Esse grupo, juntamente com o coordenador do curso e professores convidados do curso de Pedagogia, formaram um grupo maior de trabalho com reuniões quinzenais em que foram discutidos textos e propostas de formação de professores para o uso de tecnologias digitais para ensino dos conteúdos escolares no âmbito da sala de aula. Ao todo, tivemos 18 professores participantes.

Numa primeira etapa, realizamos um mapeamento de algumas políticas nacionais, internacionais e regionais que tratavam da inserção de tecnologia digital na escola, bem como a análise de conteúdo dessas políticas. Paralelamente, discutimos o aparelhamento das escolas no que diz respeito à tecnologia, tomando por base os dados do Censo Escolar e dados obtidos no site Qedu?.

Como segunda etapa, realizamos um seminário com os professores, conforme Figura 2 , objetivando conhecer as escolas, os docentes e os estudantes, de modo a identificar suas impressões sobre o uso de tecnologias digitais nos processos de ensino e de aprendizagem, quais as mudanças decorrentes dessa inserção, especificamente no aspecto curricular, além de conhecer o perfil social, tecnológico e de formação pedagógica desses sujeitos.

Figura 2: Formação para o uso de tecnologias digitais.

Fonte: Dados do autor (2018).
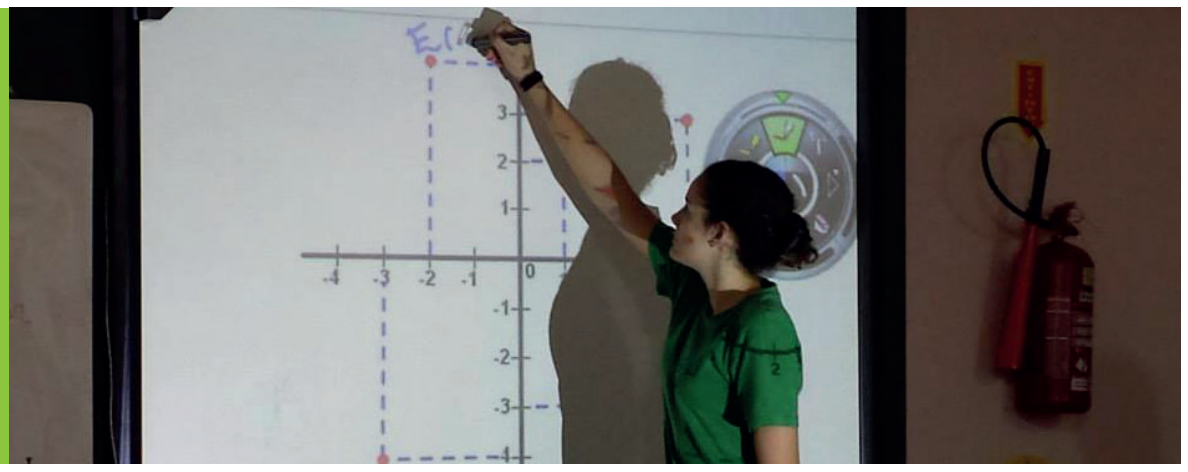

7 Para acesso ao site Qedu, ver https://www.qedu.org.br/. 
Com base na análise desses dados, questões de aprofundamento foram exploradas em um levantamento qualitativo, realizado por meio de outros textos mais complexos. Nessa etapa, fizemos ainda a realização de encontros, debates, oficinas e seminários para o desenvolvimento e compartilhamento das práticas docentes que usavam as tecnologias digitais consideradas de forma mais exitosa, especialmente aquelas que promoviam a aprendizagem colaborativa, por meio das redes on-line. Realizamos, ainda, questionários e observações com o objetivo de avaliar e acompanhar o desenvolvimento das atividades do curso.

Como última etapa, realizamos a apresentação de aulas práticas sobre o ensino de EJA e Língua Portuguesa por meio de tecnologias digitais. Ao final do curso, socializamos as práticas desenvolvidas com os acadêmicos e professores no final do semestre, juntamente aos estágios. Como finalização do curso, foi elaborado um relatório de atividades que registrou todo o rico universo problematizado, bem como publicamos artigos apresentando alguns dos resultados da prática extensionista.

Quanto ao cronograma e local previsto para oferta do curso de extensão, as aulas presenciais aconteceram no Laboratório de Informática da instituição de ensino superior, em parceria com a rede municipal de ensino, a cada 15 dias, totalizando 10 horas mensais que, ao final do período de 4 meses, totalizaram 40 horas. 0 dia e horário para os encontros presenciais foram estabelecidos com a coordenação do curso de Pedagogia, em função da disponibilidade da maioria dos inscritos no curso.

No projeto de submissão do curso de extensão ao edital da instituição de ensino superior, fizemos a interação e socialização dos trabalhos finais com a comunidade externa à instituição, juntamente às atividades de socialização dos estágios curriculares do curso de Pedagogia e, ainda, apresentação dos Trabalhos de Conclusão do Curso - TCC, feitas ao final do semestre letivo do curso.

Quanto aos acadêmicos a quem se destinava 0 curso de extensão na modalidade complementação de estudos, fizemos também uma relação entre a proposta de extensão e matriz curricular do curso. Ou seja, a proposta de extensão foi desenvolvida, especificamente, aos acadêmicos da sétima e oitava fases do curso de Pedagogia, os quais já tinham cursado a disciplina de Docência em EJA I e II e Docência da Língua Portuguesa I e II (disciplinas da matriz curricular do curso de Pedagogia) e que, por sinal, foram ministradas por nós. Desse modo, essa complementação garantia uma continuidade dos conteúdos ministrados em sala de aula nas disciplinas específicas, contudo, a partir de experiências práticas de aulas com a inserção de tecnologias digitais e posterior socialização à comunidade acadêmica.

Da mesma forma, a relação entre ensino, pesquisa e extensão estava garantida durante a oferta do curso de extensão, já que o seu desenvolvimento foi subsidiado em ações que se coadunaram nas três dimensões: extensão, por meio de ações que foram socializadas à comunidade de São José; ensino, por meio de experiências a partir das disciplinas de Docência em EJA I e II e Docência em Língua Portuguesa I e II; e, pesquisa, por meio de elaboração de relatório final da atividade de extensão, bem como a publicação em eventos ou periódicos científicos sobre a experiência e formação desenvolvidas.

\section{Resultados e discussão}

Embora não nos aproximemos muito da ideia de um movimento de resistência dos professores para 0 uso das tecnologias digitais (TD), conseguimos mapear que entre os impedimentos para esse tipo de uso existem movimentos invisíveis em torno de algumas das crenças inerentes aos professores. Eram crenças a respeito dos processos pedagógicos que os faziam, internamente, sem qualquer "[...] preocupação mais consciente" (PLACC0; SOUZA, 2006, p. 32), negligenciar os usos das TD em suas práticas escolares por meio de sentimentos como: desconforto, medo, desmotivação, desinteresse e, principalmente, insegurança profissional para lidar com as TD. Além desses, percebemos nos discursos que emergiam, também, questões relacionadas à falta de entusiasmo, curiosidade, atitude e de consciência para pensar outras possibilidades de 
aprendizagem com tecnologias diferentes do quadro, giz, caderno, etc. Mesmo assim, insistimos em caracterizar esse sentimento mais pelas nossas subjetividades, afecções, impressões e percepções, já que se faziam presentes entre os discursos dos professores por meio de algumas observações e entrevistas. Como afirmou um dos professores pesquisados, falta

"[...] um pouco do querer e da curiosidade de fazer aquilo. Porque olha só: teve formação da MS-TECH $8^{8}$ e eles mostravam que tu podes fazer uma aula integrada com o aluno em que ele participe. Aquilo que acho interessante. Acho que falta ao tentar fazer [...] porque acho que dá para explorar mais o que já tem. Falta interesse, curiosidade, boa vontade" (DADOS DE CAMPO).

Pelos dados, não são poucos os aspectos que impedem que o professor tenha voluntariamente uma pré-disposição para uma tomada de consciência esclarecida sobre como, por que e para que usar as TD com os alunos, justificada pela falta, principalmente, de segurança profissional em função do despreparo técnico/tecnológico, caracterizado, grosso modo, como falta de fluência digital: "óbvio que a partir do momento que eu começar a frequentar mais a sala e ter uma segurança maior eu acho que o sucesso das minhas aulas aqui dentro serão maior do que tem sido (sic.)" (DADOS DE CAMPO). Essa ideia de conceber a fluência digital apenas como falta de formação técnico-instrumental também tem sido apontada nas pesquisas "[...] como entrave para práticas pedagógicas inovadoras, a saber, a insegurança dos professores no uso das tecnologias digitais [...]" (CERNY, ALMEIDA; RAMOS, 2014, p. 1342).

Entre os vários aspectos que levam os professores a resistir às TD, foi em torno dessa insegurança docente que nos ativemos, dada a sua relevância quando fizemos a análise dos dados durante a pesquisa de doutorado. A insegurança para nós se demonstrou muito contraditória quando pensada como dado de pesquisa, pois ora representava um aspecto invisível, porque não se efetivava em dados quantitativos ou muito objetivos durante a coleta de dados, ora representava um aspecto muito visível, já que era comum encontrá-la entre os discursos dos professores.

Tapscott (1999) já afirmava que a maioria dos professores faz parte de uma outra geração anterior à cultura digital e inconscientemente acaba resistindo às TD porque acredita apenas nas relações presenciais e já conhecidas e, assim, considera as relações de outra natureza como efêmeras, estranhas e perigosas. Não diferente, na cultura escolar que pesquisamos, essas crenças são oriundas, na sua maioria, de práticas pedagógicas já consagradas pela tradição de ensino e que, por vezes, negavam as potencialidades dos novos instrumentos digitais. Desse modo, na sua maioria, os sujeitos extensionistas e pesquisados parecem ainda não reconhecer e validar a integração das TD em suas práticas. "Essa resistência não aparece diretamente nos discursos dos professores, mas é revelada nas suas práticas do dia a dia, nas ações e nas opções que os professores assumem quando fecham a porta da sala de aula" (ZEICHNER; SAUL, DINIZ-PEREIRA, 2014, p. 2221).

Como já dissemos, a resistência às TD se personificou nos discursos dos professores e acadêmicos, intensivamente, pelo sentimento de insegurança profissional, oriundo da dificuldade que eles têm para lidar com as alterações de suas práticas pedagógicas. São alterações representadas como mudanças e que, por sua vez, acabam sendo interiorizadas como formas de imposição e alteração das tradicionais regras pedagógicas (CUBAN, 2001). Nesse sentido, os professores acabam não se envolvendo com as mudanças por não terem condições de fazê-las, gerando um desejo contrário à mudança que denominamos de resistência, em estreita relação com a sua concepção pessoal de ensino.

Como os movimentos de resistência são difíceis de serem quantificados e vistos com muito receio pelos sujeitos extensionistas quando investigados, não abordamos durante a coleta dos dados nenhuma questão específica sobre essa categoria, até mesmo porque ela foi um achado de pesquisa que não estava previsto na investigação e nem fazia parte das nossas hipóteses. Todavia, a prática extensionista com caráter intervencionista nos permitiu perceber muitos desses movimentos, mesmo eles não sendo foco da investigação.

Nesses movimentos, "[...] os professores não podem lidar sozinhos com todas as questões

8 Nome da empresa que executou a formação sobre tecnologias digitais na rede municipal de ensino de Florianópolis/SC. 
sociais por meio da educação, isso precisa fazer parte de um projeto maior [...]." (ZEICHNER; SAUL, DINIZ-PEREIRA, 2014, p. 2221). É importante apoiá-los para que enfrentem os desafios e não culpabilizá-los pela falta de integração das TD nas práticas escolares. Em vez disso, que os auxiliemos a novas direções para "[...] continuar a trabalhar em nível local, pesquisando a própria prática, tornando os programas de formação de professores mais bem-sucedidos nas suas finalidades e agendas [...]" (ZEICHNER; SAUL; DINIZ-PEREIRA, 2014, p. 2223).

No projeto de extensão, a insegurança dos professores em relação às TD se manifestou, desde os primeiros contatos pessoais e mais ainda nas observações, pelas quais pudemos ter um olhar mais atento por meio das vídeo-gravações. Foram elas que nos permitiram observar e registrar informações que não pareciam ter tanta importância e que podiam passar despercebidas. Todavia, ao assisti-las e ouvi-las algumas vezes, fizeram-nos perceber a insegurança que se revelava por meio das expressões, impressões, percepções, comportamentos e gestos dos professores.

É uma insegurança que se acentuava nas situações de uso quando eles percebiam que as TD podiam "[...] causar perturbação na eficiência e eficácia com que habitualmente fazem as coisas sem recorrer às tecnologias (encontrando muitos aí as razões para o abandono das TIC após as primeiras tentativas sem sucesso) [...]" (COSTA, 2008, p. 514). Assim é que fomos olhando para os diferentes contextos em que os professores usavam as TD, registrando suas angústias e medos que se revelavam nos discursos, como:

"O que vou fazer na hora que me perguntarem? Me apavoro com a ideia de eles ficarem perguntando e eu não saber responder. Como é que vou fazer com essas dificuldades? É uma insegurança muito grande para o professor. Eu tinha que me preparar porque não posso ficar lá na frente passando vergonha, né! Tem até aqueles alunos que sabem mais que o professor" (DADOS DE CAMPO).

Durante o projeto de extensão, fomos percebendo nos professores que a falta de segurança profissional afetava de algum modo seus esquemas mentais e psicológicos, causando um desequilíbrio na relação de aprendizagem. Como exemplo, temos o fato de os alunos usarem as TD mais que os professores - 0 que provocava, na maioria das vezes, uma atitude de negação do próprio docente que não queria se "[...] deparar com 0 aluno que está bem preparado para lidar com tecnologias, que sabe mexer, enquanto eu não estou sabendo" (DADOS DE CAMPO).

Temos ciência de que os alunos não estão mais preparados que os professores para o uso das TD, mas não negamos a ideia de que eles se encontram mais preparados para conviver com a cultura digital e, assim, acabam se inserindo com mais naturalidade num movimento sociocultural em que apenas exploram-nas com mais curiosidade e agilidade, sem muitos medos e receios dos novos instrumentos que nos permeiam. Sobre estas últimas, temos a impressão de que as TD estão ausentes entre a maioria dos professores, ao menos no uso escolar, pois eles acabam se colocando numa zona de conforto para justificar que não têm tempo para aprender coisas novas em meio a tantas aulas e nem para mudanças nos processos pedagógicos em função de já trabalharem muito sem receber a devida valorização que merecem. Para além dessa ideia, afirmam que ainda têm pouca formação sobre como usá-las e seu uso na escola é todo pensado e arquitetado sem consulta aos próprios professores. Um dos professores chega a afirmar que "[...] não quero mudar e não vou mudar enquanto eles não resolverem isso. Enquanto não ficar tudo certo, nem vou me mexer [...]" (DADOS DE CAMPO). Ainda sobre a insegurança, os dados demonstram que eles têm mais confiança em relação ao domínio do conteúdo disciplinar e da didática para ensinar os alunos, contudo, nem todos têm a mesma confiança quando o assunto é 0 uso das TD para ensinar os conteúdos escolares. Todavia, o curso de Pedagogia "[...] continua insistindo na formação de um pedagogo genérico, com pouca atenção aos conteúdos e às didáticas disciplinares [...]", enquanto que as licenciaturas "[...] desenvolveram suas didáticas disciplinares, com pouca menção ao pedagógico (LIBÂNEO; ALVES, 2012, p. 27).

Sobre uma possível confiança a fim de ter mais segurança para uso das TD nas práticas pedagógicas, Costa (2008, p. 517) corrobora ao afirmar que:

"[...] 'sentir-se confiante' significaria ter, pois, para alguma atitude favorável, uma visão global do leque de coisas que se podem fazer com os computadores, o conhecimento concreto dos recursos que existem numa determinada área 
científica e, o que com eles é possível fazer, do ponto de vista pedagógico, com os alunos (o quê, como e para quê).

É nessa ideia que os sentimentos de confiança e segurança do professor têm uma relação com a estratégia didático-pedagógica de uso das TD que se propõe aos alunos sem colocar em jogo os seus conhecimentos técnicos/tecnológicos, pois as atividades que são oferecidas na escola são sempre aquelas das quais o professor tem domínio, tanto do ponto de vista pedagógico como instrumental (COSTA et al., 2008). É em torno desses aspectos ou 'barreiras', como afirmam Infante e Nussbaum (2010), que problematizamos a atitude e a motivação do professor para usar as TD na escola, pois essa problematização se acentua quando percebemos que "[...] para algumas das 'concepções pedagógicas' dos professores, no caso dos factores pessoais determinantes do uso, parecem ser as 'atitudes' e a confiança, os factores que parecem salientar" (COSTA, 2008, p. 517).

A respeito desses domínios pedagógicos, um dos professores afirma que "[...] domino 0 conteúdo e a didática, mas me sinto desconfortável com a máquina e 0 software; às vezes me sinto desconfortável em saber que 0 aluno domina mais os programas do computador do que eu" (DADOS DE CAMPO) e em relação aos seus medos afirma que "[...] não que eu tenha medos, porém tenho dúvidas e questionamentos além de pouco conhecimento. Tenho dúvidas sobre a forma correta de utilização das TD em aula" (DADOS DE CAMPO). De qualquer forma, "[...] quanto às questões básicas de uso já me sinto mais segura, porém quanto à aplicação pedagógica ainda me sinto pouco confiante e com muitas dúvidas" (DADOS DE CAMPO).

Um outro professor afirma: "[...] me sinto seguro em utilizar as tecnologias porque acredito que possuo conhecimento básico e aprendo com os alunos, mas tenho muitas dúvidas [...]" (DADOS DE CAMPO). "[...] Meus medos são se os aparelhos não funcionarem, os alunos não se interessarem" (DADOS DE CAMPO). Estes discursos revelam a preocupação do professor em perder a autoridade frente aos alunos e, ainda, que a falta de confiança e segurança está muito relacionada com a falta de competência técnica/tecnológica para usar as TD, ou seja, a falta de um dos elementos que chamamos neste estudo de fluência digital.

Como síntese para pôr em modo stand by a discussão sobre a insegurança do professor, os dados foram reveladores quando deixaram evidenciar que a insegurança entre os professores para lidar com as TD na escola está muito relacionada à falta de experiência de uso pedagógico dessas tecnologias para além do uso pessoal que o professor já faz fora da escola, como também para os usos menos complexos como digitar, pesquisar, comunicar-se e divertir-se. Uma falta de experiência que, por sua vez, está relacionada aos diferentes espaços, tempos e saberes que as TD promovem e aos quais os professores não estão acostumados. Tais diferenças parecem representar riscos ao professor, em maior escala, pela perda do controle e autoria da aula.

Tentando concluir este item, se por um lado a ideia de o professor se sentir seguro e confiante é um fator fundamental ao uso das TD na escola, por outro, insistimos na ideia de que a falta de segurança se relaciona aos seus receios, medos e ansiedades. A segurança, nesse sentido, quando adquirida por meio da fluência digital, pode contribuir para o professor como um movimento psicológico interno favorável ao ensino dos conteúdos escolares e que pode ser desenvolvido com o uso das TD.

\section{Conclusões}

Da nossa entrada pelo túnel digital, movido por muitas dúvidas e incertezas no início do curso de extensão, até o final deste artigo que agora publicamos, um mapa social e provisório se desenhou, enfim, se iluminou. Por entre linhas que ora celebravam, ora valorizavam as tecnologias digitais nas práticas pedagógicas, passamos, enquanto grupo de professores em formação, por territórios arenosos, movediços e atrelados aos feitiços tecnológicos que a cultura digital nos permite vislumbrar. Enquanto professores, tínhamos a impressão que estávamos ficando desempoderados de nossas crenças mais sólidas em relação à prática pedagógica em função de não nos termos apropriado, minimamente, dessas tecnologias digitais e, por isso, resistíamos aos seus encantos. 
Assim como nós, encontramos no curso muitos professores percebendo a sua prática do mesmo modo, insatisfeitos, inseguros e receosos, questionando sobre o que, como e para que fazer uso das tecnologias digitais na escola, afirmando que querer não é suficiente para usálas. Também encontramos outros professores menos aflitos e angustiados, mais confiantes e seguros, porque sabiam como usá-las, embora não propriamente para ensino dos conteúdos escolares de EJA e Língua Portuguesa. Todavia, como impactos da atividade extensionista, podemos afirmar que a comunidade de participantes (professores da rede municipal de ensino e acadêmicos do curso de Pedagogia) se apropriou muito da ideia de encorajamento e segurança para uso das tecnologias digitais que 0 curso/formação de extensão permitiu. Essa ideia foi justificativa nas avaliações de reação que fizemos ao final da atividade extensionista.

Na verdade, o que a experiência e os dados que tivemos no curso de extensão nos permitiram agora afirmar é que precisamos estar atentos sobre como os professores operam com 0 seu "não saber". Parece-nos que o "não saber", em vez de ser visto como impotência, é qualificado como potência, e por isso de forte impacto para os sujeitos participantes, já que com a socialização de algumas experiências de uso das tecnologias digitais no contexto escolar, a segurança e motivação ao uso das tecnologias aumentou, segundo relatos dos próprios sujeitos. Dessa impotência não sai nada, a não ser a estagnação. Mas isso também é culpa do professor? Parece-nos que não. Talvez precisemos devolver à cultura escolar este "não saber" e perceber como nos cotidianos escolares essa característica é incorporada sempre como necessidade de formação constante, ou seja, o contínuo desenvolvimento profissional docente. 0 que ela significa? Como ela volta e se materializa na profissionalidade docente? Ainda não temos resposta, mas entendemos que encontramos perguntas muito potentes e que valem a pena continuarem sendo perseguidas nas mais diversas atividades de ensino, pesquisa e extensão.

\section{Referências}

ALMEIDA, Maria Elizabeth Bianconcini. VALENTE, José Armando. Tecnologias e currículo: trajetórias convergentes ou divergentes? São Paulo: Paulus, 2011.

ALMEIDA, Maria Elizabeth Bianconcini. Integração currículo e tecnologias: concepção e possibilidades de criação de web currículo. In: ALMEIDA, Maria Elizabeth Bianconcini; OSB, Dom Robson Medeiros Alves; LEMOS, Silvana Donadio Vilela (Orgs.). Web currículo [recurso eletrônico]: aprendizagem, pesquisa e conhecimento com o uso de tecnologias digitais. Rio de Janeiro: Letra Capital, 2014, p. 20-38.

BALL. Stephen J. Educação global S.A.: novas redes de políticas e 0 imaginário neoliberal. Ponta Grossa: UEPG, 2014.

BONILLA, Maria Helena Silveira. A presença da cultura digital no GT Educação e Comunicação da ANPED. Revista TEIAS, v. 13, n. 30, set/dez. 2012, p. 71-93.

CASTELLS, Manuel. A galáxia da internet. São Paulo: Jorge Zahar, 2003.

A sociedade em rede - A era da informação: economia, sociedade e cultura. Vol I. São Paulo: Paz e Terra, 1999.

CERNY, Roseli Zen; ALMEIDA, José Nilton de; RAMOS, Edla. Formação continuada de professores para a cultura digital. Revista e-Curriculum, São Paulo, n. 12, v. 2, p. 1331 1347, maio/out. 2014. Disponível em: http://www.redalyc.org/pdf/766/76632206013.pdf. Acesso em: 17 mai. 2015.

COSTA, Fernando Albuquerque (Coord.). Repensar as TIC na educação: o professor como agente transformador. Lisboa: Edição Santillana, 2012. (Coleção Educação em Análise).

COSTA, Fernando Albuquerque. A utilização das TIC em contexto educativo:

representações e práticas de professores. 2008. Tese (Doutorado)-Universidade de Lisboa, 
Lisboa, Portugal, 2008. Disponível em: http://aprendercom.org/comtic/wp-content/ uploads/2013/01/TeseCostaF2008TICemContextoEducativo.pdf. Acesso em: 10 abr. 2015.

CUBAN, Larry. Oversold and underused: computers in the classroom. USA: Harvard University Press, 2001.

FEENBERG, Andrew. $\mathbf{0}$ que é a filosofia da tecnologia? Conference in the university of tokio em komaba, sob o título de "what is philosophy of technology?". Tradução de Agustín Apaza. Revisão de Newton Ramos de Oliveira. University of Tokio: Komaba, 2003.

101, 2007, p. 1287-1302.

Para que servem as escolas. Revista educação e sociedade. v. 28, n.

LIBÂNEO, José Carlos; ALVES, Nilda (Orgs.). Temas de pedagogia: diálogos entre didática e currículo. São Paulo: Cortez, 2012.

A escola brasileira em face de um dualismo perverso: escola do conhecimento para os ricos, escola do acolhimento social para os pobres. Educação e pesquisa, São Paulo, n. 21, out. 2011a.

Adeus professor, adeus professora? Novas exigências educacionais e profissão docente. 13. ed. São Paulo: Cortez, 2011b.

LUNARDI-MENDES. Geovana M. Aulas Conectadas? As práticas Curriculares no PROUCA. In: Ferrentini Sampaio; Marcos da Fonseca Elia (Orgs.). Projeto um computador por aluno: pesquisas e perspectivas. Rio de Janeiro: NCE/UFRJ, 2012.

PLACCO, Vera Maria Nidro de Souza; SOUZA, Vera Lucia Trevisan de. (Orgs.). Aprendizagem do adulto professor. São Paulo: Loyola, 2006.

PIMENTA, Selma Garrido (Org.). Saberes pedagógicos e atividade docente. 7. ed. São Paulo: Cortez, 2009.

PINTO, Álvaro Vieira. 0 conceito de tecnologia. Rio de Janeiro: Contraponto, v. 2. 2005.

RABARDEL, Pierre. Activités avec instruments et dynamique cognitive du sujet. Dans Outils et Signes. Paris: Editions scientifiques européennes, p. 35-49, 1997.

Les hommes et les technologies. Approche cognitive des instruments contemporains. Paris: Armand Colin, 1995.

SANCHO, Juana Maria; HERNANDEZ, Fernando e colaboradores (Org). Tecnologias para transformar a educação. Tradução: Valério Campos. Reimpressão 2008. Porto Alegre: Artmed, 2006.

SANDHOLTZ, Judith Haymore; RINGSTAFF Cathy; DWYER, David C. Ensinando com tecnologia: criando salas de aula centradas nos alunos. Trad. Marcos Antônio Guirado Domingues. Porto Alegre: Artes Médicas, 1997.

SHULMAN, Lee S. Those Who Understand: knowledge growth in teaching. Educational researcher, Washington, D.C., v. 15, n. 2, p. 4-14, feb. 1986.

SOSSAI, Fernando César; LUNARDI-MENDES, Geovana Mendonça; PACHECO, José Augusto. Currículo e novas tecnologias em tempos de globalização. Perspectiva, v. 27, p. 19-46, 2009.

TAPSCOTT, Don. Geração digital: a crescente e irreversível ascensão da geração net. São Paulo: Makron, 1999. 
TARDIF, Maurice. Saberes docentes e formação profissional. 15. ed. Petrópolis: Vozes. 2013.

YOUNG, Michael F. D. Conhecimento e currículo: do socioconstrutivismo ao realismo social na sociologia da educação. Tradução de Jorge Ávila de Lima. Porto: Porto, 2010.

ZEICHNER, Kenneth M.; SAUL, Alexandre; DINIZ-PEREIRA, Júlio Emílio. Pesquisar e transformar a prática educativa: mudando as perguntas da formação de professores: uma entrevista com Kenneth M. Zeichner. Revista e-curriculum, São Paulo, v. 12, n. 03, p. 2211-2224, out./dez. 2014. 